\title{
Problems and Measures of Undergraduate Final Year Projects in Higher Engineering Education
}

\author{
Zhenshan Yang \\ School of Engineering, Bohai University \\ Jinzhou, China \\ ydlut@163.com
}

\author{
Wenjiao Yue \\ School of Engineering, Bohai University \\ Jinzhou, China
}

\begin{abstract}
Final year project (FYP) is a paramount education procedure to guarantee the quality of higher engineering education (HEE). In view of the quality decline of the engineering undergraduate FYPs in the context of mass HEE, the reasons causing the quality decline of FYP in HEE including the undergraduate per se, the supervisor and the educational evaluation mechanism etc., are systematically analyzed. Drawing on some advanced practices in the development trend of HEE at home and abroad, the measures to improve the quality of FYP for the current HEE are suggested with a view of being conducive to solving the present problems of the quality decline of undergraduate FYPs in HEE.
\end{abstract}

Keywords-higher engineering education; final year project; liberal education; evaluation mechanism; educational idea

\section{INTRODUCTION}

The higher engineering education (HEE) size in China had ranked world first in 2014 [1]: there are 1047 undergraduate universities with engineering majors accounting for about 91.5\% of the total undergraduate universities, in which 14085 engineering majors are offered accounting for about 32\% of the total undergraduate majors. And there are 4.523 million engineering undergraduates, 0.6 million postgraduates which is about $32 \%$ of the students with bachelor degree or above.

However, with the expansion of education scale, the elite education has met an unprecedented challenge. The very prominent and urgent problem is the decline in quality of the engineering FYP, which is an indisputable fact. A survey on the FYP shows [2]: in $31.8 \%$ of the FYPs exists plagiarism, $25.1 \%$ inadequate creativeness, $19.8 \%$ weak of writing skill, $18.1 \%$ wider topic selection, $5.1 \%$ format not meet the requirement, where $24 \%$ of the undergraduate think that "nothing obtained" in conducting the FYP, 23.1\% think that "not only useless, but also delayed the time looking for a job", so, various arguments on how to implement FYP to achieve its expected target and whether the FYP should be cancelled or not appear constantly. FYP is a paramount element which reflects the true potential of a student in applying skills and knowledge learnt throughout the bachelor degree years. So, FYP is taken seriously in HEE at abroad universities [3-6]: it is usually regarded as a compulsory and an important teaching step to ensure the quality of HEE. In some universities in Australia and Europe, FYP accounts for roughly 300 hours which is about $6.25 \%$ of the whole engineering professional work. Considering the professional, scientific, practical,

This work was supported in part by the Educational Reform Project of Bohai University under Grant BDJG-14-YB-C-004. innovative, normative and documentary features of FYP, undergraduate students of Nigeria University are required to take a compulsory course called Research Method at the penultimate year to pave the way for the undergraduate projects at the final year. While in UC Berkeley, various lectures, seminars about research methods are organized by "the Office of Research for Undergraduate” to help undergraduate understand what the research means, how to both write the project application and make the budget, etc.

The remainder of this paper is organized as follows. In Section II, the purpose of HEE in the mass education context is proposed. In Section III, cause analysis of the decline in the quality of FYP is discussed in detail. In Section IV, measures to improve the quality of FYP of HEE are presented. And a summary is drawn in Section $\mathrm{V}$.

\section{Purpose of HEE in the Mass Education Context}

\section{A. Educational View of HEE}

China's "Higher Education Law" stipulates that the task of higher education is to cultivate senior specialized talent. However, with the advent of higher education's popularization, the cultivation goal of higher education has quietly changed. It can obviously not totally adapt to the education pattern of HEE for mass education after the massive enrollment in China.

Therefore, a comprehensive, specific, clear understanding of "talent" is given as: those who have certain knowledge or skills to carry out creative work, and to make positive contribution to advancing socialist material civilization, political civilization, and construction of spiritual civilization in the great cause of building socialism with Chinese characteristics, are talents that the country needs [7]. This concept of talent has a strong guiding significance to modern HEE in China.

\section{B. Aim of the FYP in HEE}

To cultivate the engineering undergraduate to meet the requirements of the talent definition above, the first thing to solve is knowledge acquisition: strictly classroom teaching is needed to make students master the knowledge and theory required by teaching plan. The second is knowledge application and scientific practice. FYP is conducted to solve the knowledge synthesis, which is indispensable to ensure the 
quality of the HEE. Specifically, the aim of the FYP of HEE is to train the undergraduate students' abilities to:

- Independently conduct the research;

- Apply knowledge and skills to problem-solving, analyzing and critical thinking;

- Clearly describe problems and to express the results of the research;

- Effectively communicate and cooperate with teamwork spirit;

- Explore new research knowledge and skills and develop basic skills in managing research;

- Correctly analyze and accurately operate;

- Innovate and practice;

- Scientifically think and correctly design engineering project;

- Cultivate meticulous working attitude which an engineer should have.

\section{CAUSE ANALYSIS OF THE DECLINE IN THE QUALITY OF FYPS}

\section{A. Reasons from the Undergraduate Per se}

1) The overall quality decline of the undergraduate: An outstanding feature of the mass higher education brought by enrollment increasing, is that those who were scarcely possible to be admitted to universities in elite education period acquire the opportunities to receive today's higher education. And our education system did not convert timely from the elite education, causing the contradiction between education model and object, the undergraduate are difficult to adapt to the requirement of elite education mode. a multitude of undergraduate lack basic learning ability and basic literacy which needed in pursuing engineering and technical activities.

2) The severe undergraduate employment pressure: The Chinese government started to end the policy that the government was responsible for assigning jobs to students from 1996, and the policy was entirely stopped till 2000. Comparing with the elite education period where the undergraduate have plenty of time to practice their internship to finish the FYP supervised by supervisors, the undergraduate of mass higher education, spend most of their time on job finding which results that they don't even have enough time and energy to finish FYPs on schedule with excellent quality.

3) The unfavorable government's evaluation mechanism for universities: An army of universities which are under pressure from the government on employment rate of performance evaluation have to finish the education program ahead of schedule, the four years education was compressed to about three years of work, and undergraduate had to enter into the internship stage in advance in some employers to expect to be employed. Since the undergraduates have left school for their internship, on one hand, it is impossible for them to devote major efforts to FYPs, on the other hand, supervisors have to change the way of supervising from face to face into a virtual communication.

\section{B. Reasons from the Academic Staff}

1) Undergraduate-Academic Staff Ratio is Seriously Unreasonable: The crossing from elite education to mass education resulted in the increase in the number of full-time undergraduate of higher education to more than 20 million, in 2013, 14.944353 million, in 2014, 24.681 million [8], in which the number of engineering undergraduate have reached to $30 \%$ of the total undergraduate. However, the increasing of the number of academic staff especially in local universities is far behind the pace of the undergraduate increasing. The number of the supervised undergraduates is even up to about 10-20/per supervisor. One aspect of this "batch processing” mode makes the supervisor don't have enough time to guide undergraduate, on the other hand, the academic staff is difficult to help undergraduate to determine topics with characteristics.

2) The dreadful evaluation mechanism for academic staff: The current academic staff evaluation mechanism is not in favor of encouraging teachers to concentrate on supervising FYPs. Most of the present education evaluation systems are ranking based quantitative evaluation which prefers scientific research to teaching, in which the academic staff evaluation mechanism was just rooted for quick success and instant benefits. The weight for a teacher to supervise a FYP in that mechanism is extremely low. A considerable part of the academic staff focus heavily on writing theses and applying for research projects after they completed the compulsory teaching tasks. They don't even have time to guide FYPs. Even if a teacher is responsible for FYPs, it is also hard to expect any contribution to his evaluation by his assiduous and responsible work.

3) The lack of practical experience of the academic staff: The existing talent cultivating mechanism makes quite a number of academic staff lack necessary practical training of engineering and technology. Because of the pressure of the post promotion, they have to put their efforts mainly in publishing papers, applying projects, and rarely participate in education practice and production practice, which give rise to the insufficient experiences and ability to supervise FYPs. In some universities, it is even regulated that the introduced talent may not even participate in teaching activities, let alone to guide FYPs. The FYPs of engineering undergraduate focused primarily on practical engineering, which is different from the postgraduate research. The practical experience is essential for the supervisors to effectively supervise the FYPs.

\section{The Problem of Topic Selection}

The topic selection problem is one of the major concerns at home and abroad which directly affects the quality of FYP.

1) The principle of topic selection is too rigid and inflexible: It is unrealistic to overemphasize the originality, the cutting-edge, and the authenticity of the topics of FYPs. It is 
not objective to expect a student to stand in the science development frontier to solve all the problems they meet after graduation by conducting a FYP, which is not in conformity with the objective of the ability training by FYP.

2) The topic is vague and the content involved is narrower: Such topic has no substantive content, the research purpose of which is not clear lacking relevance, feasibility and a certain breadth and depth, which leads to the research devoid of content. The work involved is not enough to either examine the effects of mastering the multidisciplinary knowledge, or assess the undergraduate comprehensive ability to use the knowledge. Meanwhile, if the topic is too narrow in scope, it may be difficult for the students to retrieve appropriate references and the undergraduate may not know how to start the FYP.

3) The level of difficulty of topics is not entirely consistent with the training goal of educating: If there is a lack of consideration for the professional characteristics and the professional training objectives and teaching requirements, it is often the case that a topic is too wide or too narrow. That would result in the topic difficult coefficient does not match its workload. It neither enables the undergraduate to complete the FYP successfully as scheduled, nor enable them to apply what they learned to engineering practice to get sufficient exercise.

\section{The Deficiency of Both the Evaluation Mechanism for FYP and the Scientific Achievement View for Universities}

The lack of evaluation mechanism for FYP and the deficiency of scientific achievement view for universities are non-negligible factors causing the quality decline of FYP. Practice indicates that without a set of rigorous scientific criterion, the FYP can only be a mere formality. To fulfill the government requirement for employment rate, the universities will artificially maximize the graduation rates. If a student can not graduate on time for failing the FYP, It will be considered an adverse effect on employment rate. Therefore, there is a contradiction between the demand for graduation rate and the strict evaluation system for FYP, which is unthinkable in the era of elite education. Consequently, establishing a scientific achievement view for universities and a scientific FYP evaluation mechanism, are the only road to guarantee the quality of FYP to realize the quality of HEE.

\section{MeAsures to IMPROVE THE QUALITY OF FYP IN HEE}

\section{A. Establish the Reasonable Goals of FYP}

1) Establish a multi-level based diversified talent cultivation orientation: China's "Higher Education Law" states clearly that diversified forms should be taken to actively develop the cause of higher education. The diversified forms indicate that the training goals and specifications may also be diversified, and then the curriculum system and content of courses may definitely be diversified, thus the education quality evaluation standard must be diversified. The quality of HEE which is a multidimensional concept cannot be measured by a unified scale. Different Universities which are with different objectives cultivate undergraduate at different level to meet different social needs. Different training goals result in the different requirements and expectations of FYP.

2) Determine the reasonable anticipated goal of the ability cultivation by FYP: The previous survey on FYP demonstrates that [2], 31.5\% of the undergraduate students frown on abolishing the FYP, 52.9\% of them affirm the role of FYP, among which, $15.3 \%$ of the undergraduate students think they gained greatly in completing their FYP, 37.6\% think that they obtain just a little bit. Based on the multi-level and diversified talent training objective, FYP is employed to make undergraduate being familiar to solving engineering or technical problems, to strengthen cognitive ability, work ability, cooperation ability and survival ability.

Therefore, the training of FYP should mainly focus on the abilities of knowledge analysis and synthesis, reference retrieving and synthesizing, observing and handling, description and analysis.

\section{B. Establish the Multi-channel Topic Selection Mechanism}

Topic selection is a key factor affecting the quality of FYP. Draw lessons from the advanced practices at home and abroad, the topic selection mode is conducted as follows in the light of the specific situation in our country.

1) Negotiation based topic selection: The supervisor may offer a list of research projects based on the research interests of his own for undergraduate, or with the approval of the supervisor, students may choose other topics in the direction suggested by the supervisor. Some universities in Australia and Europe commonly used this way for the undergraduate to determine the FYP topics [3]. This way is conductive to exerting undergraduate subjective initiative to improve the quality of FYP.

2) Industry based topic selection: The research projects are derived from the industry, and supervised by the school in partnership with the enterprise. The joint-supervision of FYPs by Purdue University and India manufacturer is a successful example [9]. On one hand, it enables the undergraduate to touch with the engineering practice early, on the other hand, it also makes the research objectives of academic staff tend to be more reasonable and practical. At the same time, the social influence of the university is manifested in solve engineering problems for the enterprise.

3) Scientific research project based topic selection: The topic of FYP is parts of the research projects from the supervisor. Letting undergraduate to join the supervisor's research team and taking the subtask of the entire project as the FYP is the international practice [10], which either improves the overall efficiency of scientific research, or lay an actual combat foundation for the scientific research of the undergraduate, and alleviate the current contradiction of the undergraduate/academic staff ratio to a certain extent.

4) Science and technology competition activities based topic selection: There are generally certain advancements and comprehensiveness in the science and technology competition activities for undergraduate students, such as mathematical 
challenge cup competition, competition of smart car, mathematical modeling competition, the electronic design competition, process control simulation robot contest, ACM international programming competition, etc.

The topic of above competition activities conforms to the requirements of the FYP topic selection. However, after the activities, there is still a problem of analysis and synthesis of the competition activities. How to conclude and summarize in clear, concise language the activities to a qualified FYP will be a very good academic training for undergraduate students.

5) Interdisciplinary team collaborative way based topic selection: The interdisciplinary team collaborative way based topic selection should be advocated. As a matter of fact, the actual scientific research or engineering project is such an interdisciplinary team collaborative process that it is almost impossible for one individual to independently complete. Consequently, the Engineer Certification Committee in the United States and Canada stipulates that before the graduation of an undergraduate student is accredited, he should be with the medium level capacity to participate in multidisciplinary team and plays a role in it, therefore, a more complex engineering problem, usually need to partition into relatively simple subtasks and finished by participants respectively.

\section{Undergraduate Scientific Research Achievements Based Substitution of FYP}

If an undergraduate student publishes a research paper, and reaches the required level of FYP recognized by the Expert Evaluation Committee as per the reasonable review mechanism, the published paper will substitute for FYP. Furthermore, research papers achieving excellent level, can be rated as excellent FYPs. However, FYP is a beginning of training undergraduate to pursue the future research and engineering practice. Comparing the present HEE curriculum system with that of world class universities, there is still some way to go. So, on the whole, under the current HEE system in our country, it is difficult to achieve the purpose of cultivating engineering undergraduate if FYP is canceled.

\section{Establish the Academic Training Mechanism for Undergraduate Students' $R$ \& D Abilities}

Undergraduate students have mastered solid theory and basic skills; they lack training of what to do, how to cooperate and how to experience themselves in work and cooperation with others. They do not even clearly understand how to determine the technical route of a given problem and how to write a research paper according to the results. Draw on the experience of the University of Nigeria and the UC, Berkeley; the related academic training should be conducted throughout the school year. We offered several series of lectures "The basic method of scientific research", "how to write and publish research papers", "how to use the network to retrieve literature" and "how to carry out cooperation study", etc. The favorable result is obtained.

\section{E. Establish a Scientific and Reasonable Stimulation and Evaluation Mechanism for Students and Academic Staff}

Drawing on the experience of UC, Berkeley, in order to encourage undergraduate to express their academic insights and stimulate their research interests, compulsory credits is provided for FYP, undergraduate may obtain corresponding credits by FYP; the school will finance or partly finance the expenditure for literature retrieval and materials, subsidize and encourage undergraduate to publish research papers, to participate in academic activities; excellent results should be rewarded and included in the student archives; establish the corresponding stimulation mechanism to encourage academic staff to supervise FYP and add the corresponding work to the total workload; the academic staff of prize-winning by supervising FYPs would be rewarded with a proportionate incentives, and the work on FYP will be a preferred criteria for his scientific research evaluation and professional title promotion, and so forth.

\section{CONCLUSIONS}

The diversified and multi-level characteristics of social demand for talent make the HEE face a huge challenge. As the paramount learning stage required in the HEE cultivation target, FYP is the important practical phase and effective measures to develop engineering undergraduate creative ability, innovation spirit and cooperation ability and survival ability. So based on the above, the measures should be taken as follows:

- $\quad$ Determine the scientific and rational FYP expectations;

- Establish the multi-channel FYP topic selection mechanism;

- Advocate the "inquiry-based learning" pattern to stimulate undergraduate intrinsic motivation;

- Give full play to the undergraduate subjective initiative and learning potential;

- As advanced placement of FYP, the relevant academic training for undergraduate should be conducted in a planned way;

- Establish a scientific and reasonable stimulation and evaluation mechanism for undergraduate and academic staff.

\section{REFERENCES}

[1] H. Deng, "China's higher engineering education has received international recognition (In Chinese),” Guangming Daily, 2013-08-21.

[2] Z. Jian. He, "Undergraduate thesis is not worth conducting (In Chinese),” China Youth Daily, 2007-12-17.

[3] Ku H.S-L, "Final year engineering projects in Australia and Europe," European Journal of Engineering Education, vol.35, pp. 161-173, 2010.

[4] Ifedili. C. J., "Omiunu. S. Supervision of undergraduate final year's project requirement in Nigerian Universities - the way out of the wood," Asian Culture and History, vol. 4, pp. 153-158, 2012.

[5] Ferlin. E. P., Pilla Junior. V., Cunha Jose C. C. "The graduation thesis in the computer engineering program at unicenp," Proc of the 33rd ASEE/IEEE CO Annual Conf on Frontiers in Education, Boulder, pp. F2F6-F2F10, 2003. 
[6] Strong. S. D. "An approach for improving design and innovation skills in engineering education: The multidisciplinary design stream,” Int. J. Elec. Eng. Educ., vol. 28, pp. 339 - 348, 2012.

[7] CCCPC, Decision on Further Strengthening the Talent Work (In Chinese). Beijing: Party Building Books Publishing Hause, 2004.

[8] National Bureau of Statistics. Students in schools of higher Education [EB/OL] (In Chinese). National Data . see:

http://data.stats.gov.cn/search/-keywordlist2 (access time: 2015- 09- 04).
[9] Pioltte. M., Kovaichelvan. V., Chand. S., "Global experiential projects with a manufacturer in India: Insights from five years of experience," INFORMS Trans on Education, vol. 13, pp. 31-34, 2012.

[10] Nur F., Syaimak A. S., "The trend in industrial computing's final year projects at school of information technology," Procedia Social and Behavioral Sciences, vol. 59, pp. 144-149, 2012 